\title{
O cuidado com o corpo e a obrigatoriedade da saúde: sobre hexis e poder na modernidade
}

\author{
Body care and health obligation: hexis and power in modernity
}

Rubia Carla Formighieri Giordani (https://orcid.org/0000-0001-5698-7981) ${ }^{1}$

Marisete Teresinha Hoffmann-Horochovski (https://orcid.org/0000-0002-5220-3614) ${ }^{2}$

${ }^{1}$ Departamento de Nutrição, Universidade Federal do Paraná (UFPR). R. Pref. Lothario Meissner 632, Jardim Botânico. 80210170 Curitiba PR Brasil. rubiagiordani@gmail.com ${ }^{2}$ Departamento de Sociologia, UFPR. Curitiba PR Brasil.

\begin{abstract}
The aim of this essay is to provide a brief reflection on the contemporary ethics imposed on the body, which points to a growing responsibility and obligation of the individual regarding healthy and correct ways of living. The central object of analysis is the body constitution in modernity, in a space of technical intervention, problematizing contemporary forms of body care, such as diets and physical exercises, which express taxonomies that come from the matrix of meanings in modernity.

Key words Corporality, Science, Health, Society
\end{abstract}

Resumo O presente ensaio tem por intuito realizar uma breve reflexão da ética contemporânea imposta ao corpo, que aponta para uma crescente responsabilização do indivíduo e sua obrigatoriedade em relação às maneiras sadias e corretas de viver. O objeto central de análise é a constituição do corpo na modernidade em espaço da intervenção técnica problematizando as formas contemporâneas de cuidados com o corpo, como a dieta e os exercícios físicos que expressam taxionomias da matriz de significações da modernidade.

Palavras-chave Corporalidade, Ciência, Saúde, Sociedade 


\section{Introdução}

O corpo assume posição privilegiada na sociedade contemporânea, concedida e construída pelo discurso científico e mediático que é instrumentalizado no interior de uma cultura sustentada pela matriz judaico-cristã como sua legisladora de espelhos ${ }^{1}$. Nesses termos, a sociedade ocidental consagrou ao corpo um status iconográfico, em que, em uma relação de finalidade, tornou-se objeto de orgulho e zelo para o investimento narcísico $^{2}$ e um projeto reflexivo de autoidentidade ${ }^{3}$. Todavia, para ser contemplado, é antes ritualizado pelas técnicas modernas e simbolicamente transformado em expressão radical da vontade de ser do sujeito da modernidade.

Matéria elusiva sempre aberta à negociação de um novo sentido, o corpo é a todo momento objetivamente ressignificado em profundo acordo com a ordem simbólica do mundo social, revelando-se na distinção imagética do desejável e do temido ou, ainda, do aceitável e do recusável. Na perspectiva moderna, o espelho reflete impositivamente o idealmente construído em torno do corpo e reatualiza constantemente noções como belo, feio, saudável, vigoroso, jovem.

Nessa construção social, o corpo é fato social total que integra as dimensões da cultura vivida, interiorizada e marcada na carne; é a expressão em forma da matéria viva desenhada em linhas e curvas, preferencialmente, em acordo com os signos dados pela lógica das instituições sociais $^{4,5}$. Linhas retas, formas polidas, movimentos rápidos e livres, funcionalidade e elegância para a existência hipoteticamente democrática do corpo no bojo da modernidade tardia. Nela, as práticas corporais são instrumento e finalidade que traduzem tanto a incorporação de valores éticos e estéticos contemporâneos, que elegem a vida saudável e ativa como prioritária, quanto à valorização da autoidentidade. Refletir sobre essas questões é o objetivo deste artigo, de cunho ensaístico, que se apoia fundamentalmente em literatura sociológica contemporânea.

O texto está dividido em duas partes, além desta breve introdução e das considerações finais. Em um primeiro momento, procurar-se-á expor, de um lado, como as articulações entre corpo e saúde perpassam a dimensão de constituição do individualismo na modernidade, sua emancipação das tradições e a autonomia no plano da reflexividade; de outro, como a apropriação do corpo pelo discurso biomédico vem se transformando e adquirindo potencial perturbador de governo da energia da vida, por meio da intro- jeção de modos biológicos corretos de viver e da disseminação de formas de autogoverno mediante o uso da técnica e da ciência envoltas em uma moralidade.

Já num segundo momento, ao perscrutar os caminhos percorridos por essa moralidade, descortina-se uma intencionalidade em seus usos que, além dos processos de contenção dos corpos e domesticação, impõem modos legítimos de ser e estar no mundo e na vida em sociedade propositalmente inalcançáveis. Destinam-se, dessa forma, a cumprir mecanismos de violência simbólica que sustentam a construção de corpos hegemônicos. Da relação entre as estruturas sociais e a subjetividade (esta última forjada no interior destes processos), reproduz-se e dissemina-se a matriz - de percepção e apreciação - legisladora de espelhos no ocidente moderno ${ }^{1,6}$.

\section{O corpo e a vida saudável}

O sujeito do Iluminismo, provido da razão e da consciência, e o Humanismo, que consagrou o homem no centro do universo, são as marcas históricas para emergir a condição do individualismo. Na modernidade, o indivíduo cognoscente, destacado pela filosofia cartesiana, autônomo e livre em suas faculdades mentais e transcendendo as tradições enraizadas no corpo social, inaugura uma nova compreensão sobre o sujeito moderno. Compreensão que indica a rede de interdependência entre indivíduo e sociedade, na medida em que traduz as transformações ocorridas na formação social e na estrutura psíquica e comportamental dos indivíduos ${ }^{7,8}$.

No exercício de pensar a si mesmo, o sujeito moderno se emancipa das tradições fixas e olha para seu próprio corpo enquanto constructo ético de uma liturgia diária de esforço e aplicação de técnicas precisas. $\mathrm{O}$ corpo passa a representar um investimento social e simbólico - embora individual - que designa, tanto na forma quanto na expressão, o espetáculo de si orquestrado em uma estética da existência. A vida se torna uma obra de arte, repleta de estilo e valores estéticos e éticos, artesanalmente e permanentemente construída pelo e para o sujeito que objetiva, por meio do zelo consigo mesmo, viver bem no mundo que está inserido9. A estética da existência, no dizer foucaultiano, resulta de uma relação de si para consigo, de uma transformação constante de si; a existência tomada como matéria flexível para a (re)elaboração de si mesma. O corpo é o domínio desta estética de si, locus de microlutas, normatizações e resistências. O corpo traduz o ser, gra- 
dativamente concebido para si e para os outros, para atender expectativas igualmente construídas por si e pelos outros. O corpo olha e se expõe ao olhar, vê e também é visto. Nesse cenário, uma nova ética corporal vai sendo edificada e o discurso científico tem um papel importante, pois atua como engenho conveniente na construção do corpo funcional, produtivo e hígido, pretendido no âmbito dessa nova ética que rege a vida.

Foucault, ao pensar o corpo na modernidade, analisa os mecanismos disciplinares de manipulação da máquina corporal que visam fundamentalmente a aumentar a utilidade e o grau de dominação ${ }^{10}$. Apto e dócil, o corpo interioriza os comandos do poder disciplinar e, concomitantemente, de submissão e controle. O espaço de vigilância, outrora favorecido pela estrutura panóptica, passa a ser incorporado pelo indivíduo com o desenvolvimento do autocontrole e do domínio de tecnologias voltadas para o aperfeiçoamento de si. Para Foucault, a "governamentalidade" para a governabilidade da vida engendra biopolíticas ${ }^{11}$ calcadas na gênese do conhecimento; seu poder manifesta-se nas políticas do corpo e na mente e, nesse sentido, o corpo passa a ser elaborado como constructo de poder e saber no processo de racionalização da sociedade moderna. A industrialização, o controle burocrático, o manejo científico, a disciplina e a regulação apoderam-se do corpo que abandona a humilde condição natural e espontânea de outros tempos ${ }^{12,13}$.

Por sua vez, o processo de racionalização e, por extensão, de desencantamento do mundo, possibilitado principalmente pelo desenvolvimento técnico-científico, caracteriza a moderna sociedade ocidental ${ }^{14}$. O conhecimento acerca dos objetos, do mundo e da natureza é racionalmente construído e organizado, de forma planejada, calculada e previsível. E esse processo está presente tanto nas esferas política, econômica e administrativa do sistema capitalista, por meio de uma burocracia eficaz, quanto em outras dimensões da vida humana. Gradativamente, todas as atividades ordinárias são realizadas a partir de uma racionalidade, inclusive as que dizem respeito às necessidades fisiológicas.

Uma visão mecanicista do corpo se consolida a partir dos séculos XVII e XVIII: a formulação de um conhecimento anatomofisiológico e a incorporação da biodinâmica, com o conceito de calorias, acentua o papel dos alimentos no funcionamento do corpo/máquina e o equilíbrio entre ingestão e gasto ${ }^{15-17}$. Há cálculo e organização nas escolhas alimentares. A dieta moderna - que se desenvolve com o nascimento da ciência dos alimentos e da nutrição, dos conceitos da termodinâmica e das quilocalorias, além da constituição do campo da clínica médica - amplia o discurso científico sobre regras de comer e modelos adequados de controle da vida. Vale ressaltar que o próprio termo dieta, que etimologicamente expressava um modo político da vida ateniense na antiguidade, ganha na modernidade um particular reforço pelo sistema terapêutico convencional, com toda a regimentação alimentar e física calcada no conceito ocidental de "estilo de vida saudável"12.

A partir dessa nova racionalidade científica, a biomedicina apropria-se progressivamente da vida, do corpo e da saúde, estabelecendo a normalidade biológica e a normatização dos comportamentos $^{15,17-19}$. Esse conhecimento, transformado em técnica, não só se dissemina como penetra e perpetra nas mentes e nos corpos dos indivíduos, clamando pelo uso adequado das energias biológicas para uma vida produtiva, saudável e responsável ${ }^{20}$. Nessa matemática da vida, a ciência da Nutrição racionaliza o ato de comer, evidencia os balanços energéticos e a composição química dos alimentos - estes não mais ingenuamente denominados "comida", mas por vezes equivocadamente "demonizados". Arnáiz ${ }^{16}$ faz uma reflexão fundamental dessas transformações em nossa sociedade quando assinala que,

[...] la normalización dietética se ha concretado en torno a la dieta equilibrada, esto es, um patrón alimentario basado em la restricción o promoción del consumo de ciertos alimentos [...] y la prescripción de un conjunto de pautas [...]

Predomina, portanto, de acordo com a autora, uma normalização alimentar baseada na ideia de dieta equilibrada. Essa nova racionalidade que orienta o comportamento alimentar tem suas razões e seus desdobramentos nas novas corporalidades contemporâneas, que se constituem sob a égide do neoliberalismo. O corpo, em conjunto com o conhecimento, se torna um diferencial do sujeito empresarial, que investe incansavelmente na valorização de si mesmo buscando sucesso e realização (pessoal e profissional). Uma nova razão do mundo, na visão de Dardot e Laval ${ }^{21}$, é instaurada pelo mercado global que, ao estabelecer regras e estimular a competição, justifica as desigualdades, redefine as relações sociais e as percepções individuais. $\mathrm{O}$ sujeito empresarial almeja autossuperação, autossuficiência, alta performance (em todas as esferas da vida), domínio de si mesmo e, consequentemente, controle das emoções e do corpo, a exemplo do agora cultuado atleta de alto nível. "Não há tempo para 
perdedores"! O bom desempenho, sinônimo de prazer, se torna a máxima a ser alcançada, afinal "somos campeões"!

No interior do discurso técnico-científico e das práticas sociais contemporâneas, alinham-se novas liturgias corporais com estratégias de manejo racional do corpo. Vivem-se de modo menos intenso as sensações da dor e do desconforto físico, aliviadas ou controladas por alimentação saudável e equilibrada, ingestão de vitaminas e minerais e/ou medicamentos cada vez mais precisos. Ao mesmo tempo, experimenta-se um corpo que combina inovação tecnológica, técnicas cirúrgicas, próteses e as diversas modalidades do fitness. Um corpo que é controlado e moldado por práticas e técnicas e, concomitantemente, ressignificado pelo debate científico. Um corpo que, por um lado, propicia uma maior sensação de autonomia e de liberdade, na medida em que é percebido enquanto resultado de cuidados e escolhas individuais, e, por outro, carrega e exprime os valores éticos e estéticos do grupo no qual está enraizado. Um corpo que, segundo Giddens ${ }^{3}$, possui uma "dupla significação" em termos de "agência": é controlado individualmente, possibilitando a manutenção da autoidentidade e é mostrado, exibido socialmente ${ }^{3}$. A biografia e a história, individual e social, estão entrelaçadas na compreensão e na expressão do corpo em tempos contemporâneos.

As práticas corporais - como ginástica, dietas, cosméticos e rituais de higiene - radicalizam na cultura atual, de acordo com Góes e Villaça ${ }^{22}$, o biopoder foucaultiano e, ao mesmo tempo, denotam uma certa imprecisão entre disciplina e prazer. O indivíduo, ao buscar a saúde perfeita, a beleza e a luta contra a degenerescência física/ biológica, envolve-se em constructos de poder sutilmente elaborados em favor da ética contemporânea que designa ao corpo o duplo imperativo da saúde/estética. Os investimentos do poder tomam outra forma e, conforme os autores, ao invés de se expressarem através do binômio controle/repressão se apresentam como sedução/ estimulação.

Os reflexos do espelho assumem, assim, contornos específicos na cultura moderna: firmes, rígidos, que, contudo, ganham formas variadas. Nesses contornos, uma nova noção de beleza é construída e idealmente promovida pelo mercado da moda, pelas mídias sociais e pelos meios de comunicação de massa. O belo é agora representado pelo corpo jovem (independentemente da idade cronológica), firme, ágil e saudável, esculturalmente moldado por práticas desportivas, alimentação equilibrada, vitaminas e minerais, técnicas cirúrgicas, entre outros. Das passarelas às ruas, das academias aos parques, as belas formas corporais (firmes, fortes e saudáveis) são almejadas, acionadas e replicadas.

Não obstante, não se pode deixar de marcar a emergência de processos de subversão a essa ordem ou que desafiam a norma imposta. Essas dinâmicas de enfrentamento de corpos hegemônicos, de formas de se viver com a dominância de uma moralidade das disposições e comportamentos, envolvem novas conquistas de sentido que requerem reconstruções e outros movimentos corporais de resistência em constante luta de e por espaços. Bem ilustrada fica essa perspectiva quando são trazidas à tona as pautas políticas dos movimentos sociais e coletivos ligados às minorias LGBTQ, os debates capitaneados pelo feminismo latino-americano indígena e as agendas do movimento feminista negro. Reivindicam-se aí outras disposições para o ser e o estar no mundo, alicerçados pela politização do corpo e a soberania corporal. São corpos historicamente invisibilizados, estigmatizados, que clamam seu espaço e legitimidade na esfera pública, agenciando outros usos, novas representações e demandas emergentes de atenção à saúde. Faz-se do corpo um território político para a contestação.

Apesar dessa contrabalança ao sistema, no interior deste a variação da plástica corporal ocorre dentro de repertórios similares. Há expansão de possibilidades, mas o clima não é de todo democrático. Apesar das pluralidades, as corporalidades à mostra são múltiplas expressões de um mesmo projeto político voltado à construção do indivíduo hígido e que sabe viver "corretamente" de modo a não desperdiçar a energia da vida. Este projeto político necessita atravessar o corpo.

Uma das razões que explica parte dessas transformações nas práticas e nas representações corporais é fornecida por Baudrillard ${ }^{2}$. O autor sugere que o corpo adquiriu valor-signo extraordinário na cultura moderna, assumindo a qualidade de "ser o mais belo objeto de consumo". Para tanto, exemplifica como padrões de beleza do feminino são construídos no interior da sociedade de consumo ocidental: “... é evidente (basta apenas lançar um olhar sobre outras culturas) que beleza e magreza não possuem qualquer afinidade natural. A gordura e a obesidade também foram belas noutros lugares e noutros tempos"2.

Outra razão a ser destacada encontra-se no fato de que a saúde se torna cada vez mais complexa, e os limites entre o bem-estar e a doença passam a ser mais nebulosos, ou melhor, tênues, 
visto que os conhecimentos científicos são marcados pela dinamicidade e por constantes reatualizações. Entre as consequências, destaca-se a rapidez presente na (re)elaboração de conceitos como "vida saudável" e "dieta adequada", além da persistente intelectualização da vida cotidiana para a formação de novos hábitos que incorporem técnicas apuradas para a promoção da também nada estanque noção de bem-estar.

Atualmente, o bem-estar tornou-se sinônimo da adoção de um estilo de vida que prioriza atividades físicas e práticas de bioascese, com o indivíduo especializando-se cada vez mais no "controle de si mesmo, administrando as próprias taxas de colesterol, peso, ingestão de álcool e tudo que possa macular a saúde"23. Num cenário de maximização da saúde e de novas tecnologias que operam sobre o corpo, há uma responsabilização do indivíduo, que resulta tanto em autovigilância, autocontrole e autocuidado quanto em culpabilização $0^{24,25}$.

Se a forma e o desempenho do corpo não atendem à norma, o responsável é o indivíduo que não investe em sua construção, que não zela por si a contento. Para Cerqueira ${ }^{23}$, "corpo, saúde e beleza se fundem. O corpo é construído, consumido, padronizado no sentido de sua purificação e apuração estética". É produzido por uma alimentação em que o alimento assume uma funcionalidade estritamente nutricional, pela racionalização dos movimentos corporais agora calculados e planejados em função das taxas de energia que podem "queimar" e partes do corpo que podem modelar. As mudanças na sua governança são com vistas a uma performance idealizada e orientada pela reposição de hormônios; um aprimoramento pelos usos off-label, pela reconfiguração de eventos corporais e psíquicos mediados por uma solução farmacêutica com o emprego de medicamentos para fins não médicos ${ }^{26}$.

A concepção normativa de vida saudável leva à patologização do sedentarismo e à supervalorização da atividade física, planejada e calculada, que passa a ser vista como espécie de remédio para a vida ${ }^{24,25}$. Isso simplifica tanto a noção de saúde quanto a motivação para praticar atividades físicas que perdem, nesta lógica, seu "caráter hedonístico". Ferreira et al..$^{25}$ afirmam que: "Assim como é comum reduzir-se o amargor de um remédio diluindo-o em substâncias doces ou antevendo a cura da doença, não raro busca-se a motivação para a prática da atividade física em outro lugar que não nela própria”. Desse modo, o sedentarismo precisa ser tratado e o indivíduo que não o faz deixa de ocupar-se de si, ele assume um estilo de vida que não condiz com o saudável. Novamente, a responsabilização e a culpabilização individual em nome da ética contemporânea imposta ao corpo e da chamada "vida saudável". Em um mundo que exalta o sujeito com alta performance em todas as esferas da vida, no dizer de Dardot e Laval ${ }^{21}$, praticamente não há espaço para o que não se adapta e não valoriza a si mesmo; isso intensifica a culpa individual e, por extensão, promove sentimentos de solidão, depressão e ansiedade.

Nesse cenário, a saúde passa a ser considerada muito mais responsabilidade do indivíduo, pois se considera que ele tem a opção da escolha, em que pese os condicionamentos culturais que forçosamente têm impelido a sedução por todo tipo de comida rápida e conforto físico da vida moderna propiciado pelos automóveis, elevadores, controle remoto e os dispositivos móveis. Está o indivíduo diante da dívida do prazer com a disciplina, entre a sedução da diversão instantânea e fugaz, o apelo da comida rápida ultraprocessada sempre à disposição - com rótulos sobre informação de energia - e o dever para com a queima calórica e o treino físico para a sua redenção. $\mathrm{Na}$ dupla culpa do excesso do sabor (embora artificial) e do saber (muitas vezes manipulado ou ocultado pela indústria alimentícia), do pecado e da penitência, o indivíduo é estimulado a consumir conceitos de saúde e estilo de vida saudável, cambiantes a todo o momento e provocativos de novos desejos e novas seduções ${ }^{27}$. A proclamada liberdade de escolha é questionável e aponta que, no que diz respeito às práticas corporais, é necessário considerar, dentro da perspectiva elisiana, a interdependência entre indivíduo e sociedade ${ }^{7,8}$.

\section{Hexis corporal: expressão de práticas normativas e do poder simbólico}

Há rastros no território corporal de movimento de um tipo de poder simbólico. São práticas, mentalidades, representações e sentimentos em relação ao corpo que falam de novos mecanismos de controle. Essas corporalidades hegemônicas instrumentalizam formas de um tipo de poder que por seu meio - o corpo - transfiguram relações de dominação já instituídas. A violência simbólica se manifesta pelo prestígio e reconhecimento como legítimo desses discursos sobre o corpo, sobre como deve ser e deve estar, porque são formas absolutamente naturalizadas de socialização e que, portanto, suavizam a desproporção e a opressão ao utilizar o encanto ao invés da coerção física ${ }^{28,29}$. A aplicação da técnica 
sobre o corpo para que ele ocupe o seu devido lugar no espaço social, e tenha a sua estética e funcionalidade produtiva assegurada, se refere às biopolíticas que, ao representarem o discurso legítimo, inculcam normas e necessidades manifestas no corpo.

O poder disciplinar, que visa o corpo individual, e a biopolítica, que tem como objeto a vida da população, foram amplamente exploradas por Foucaul ${ }^{10}$ no contexto de fortalecimento do Estado-nação e normalização da sociedade. Por meio do biopoder, os Estados modernos utilizam técnicas de controle e disciplina sobre o corpo do indivíduo e sobre a população, regulando comportamentos, gerenciando a saúde, taxas de natalidade, mortalidade e expectativa de vida, alimentação, sexualidade, entre outras ${ }^{10}$. A biopolítica contemporânea, por sua vez, fruto de avanços tecnológicos e científicos, tanto atua na produção de políticas públicas de saúde reivindicadas por grupos que lutam por direitos sociais, quanto promove obrigações específicas para a comunidade biológica. Nessa última, o sujeito desenvolve relações específicas consigo mesmo e com os outros, a partir de um tipo de conhecimento em nível molecular, de forma a poder gerir riscos genéticos. Em tempos de biotecnologia altamente preventiva, uma nova cidadania é constituída, a biológica, "dotando os sujeitos de uma identidade social cada vez mais pautada em predicados corporais" ${ }^{30}$, conjuntamente a uma nova forma de sociabilidade, a biossociabilidade, que faz "referência a grupos de pessoas que redefinem suas identidades individuais e coletivas em torno de suas próprias doenças ou susceptibilidades..." ${ }^{30}$. Nesse rumo, as tecnologias de incorporação (hormônios, aparelhos auditivos, próteses, cadeiras de rodas, "tecnologias de melhoramento" entre outros) são fundamentais nesse processo, na medida em que, atuando sobre os corpos, constituem identidades e problematizam a noção de normalidade ${ }^{19,30}$.

Bourdieu $^{29}$ ressalta que as disposições corporais e os sinais diacríticos manifestados no corpo revelam esquemas classificatórios que só podem ser compreendidos quando localizados dentro do espaço social ocupado pelo indivíduo. Isso nos levaria a decodificar todo o estilo de vida de um grupo social, o comportamento alimentar e a pedagogia corporal, não apenas como objetivação dos imperativos econômicos, mas, sobretudo, como uma forma suavizada das contradições sociais objetivadas na preferência por determinados repertórios da vida social (certos objetos e padrões de atitude). Por assim dizer, os estilos de vida retraduzem posições nas estruturas das rela- ções sociais, expressando e definindo diferenças objetivas nas condições de existência.

Dessa forma, as práticas são produtos da relação dialética entre o habitus - a disposição incorporada - e as condições materiais de existência que permitem a reatualização desse habitus ${ }^{28}$. Este pode ser compreendido como produto da interiorização das estruturas externas; esquemas que são interiorizados e que permitem engendrar os pensamentos e as ações de uma cultura, fornecendo um sentimento de pertencimento social e, ao mesmo tempo, marcando esse enraizamento. A exterioridade interiorizada, presente em nossas mentes e em nossos corpos, forma um sistema de disposições duráveis e socialmente variáveis. O habitus é criador e inventivo, mas dentro dos limites de suas estruturas; é gerador e unificador, pois permite colocar em ato e dar razão à constância das disposições, dos gostos, das preferências, construindo e compreendendo de maneira unitária as dimensões da prática. É estrutura estruturante e estrutura estruturada ${ }^{28}$.

As imagens que circulam enquanto marcadores simbólicos dos contornos do corpo inscrevem atributos na forma representada, por exemplo, pela magreza feminina, o desejável corpo enxuto, seco e contido, e por exclusão o seu oposto, o corpo percebido como disforme, classificado hiperbólico, ou representado como extravagante. As construções de sentido para a realidade do mundo social estabelecem arranjos para a globalidade do social que é vivida enquanto uma dimensão comunal de sentido em que as formas corporais se afinam a determinados modelos identitários.

Para Bourdieu, os sistemas simbólicos realizam uma função política enquanto dispositivos aceitáveis e plausíveis da imposição das ideias e dos valores, na medida em que garantem de maneira tênue a aceitação e a naturalização dos constructos de sentido. A imposição de uma hexis corporal, enquanto violência simbólica legítima de uma forma de ser/estar no mundo, de legislar imagens que expressam as taxionomias da matriz de significações da cultura dominante, constitui apenas uma das muitas outras ações pelas quais são inculcados limites ou classificações sociais ${ }^{28}$. A violência simbólica expressa tais imposições sentidas (de forma consciente ou inconsciente), incorporadas e reproduzidas, de modo a se aderir às imagens e seus significados. Uma adesão e pertencimento ao imaginário compartilhado culturalmente.

Sobre a violência simbólica presente no sistema de gênero, que institui e organiza as relações sociais, no campo das normatizações e normali- 
zações de viver, as imposições de marcas culturais que representam o feminino no corpo da mulher, por exemplo, são emblemáticas. Define-se aí toda uma liturgia diária em relação ao cuidado corporal, às práticas consideradas de saúde, aos hábitos de higiene e asseio pessoal, à produção da imagem idealizada com um modo de vestir particularizado, à cosmética, à mecanização e à programação da atividade física, ao comportamento alimentar e às racionalidades que orientam as decisões alimentares e que claramente guardam relação direta com o poder e o controle sobre um corpo que materializa o ideário socialmente ensejado do feminino. Assim, as tecnologias corporais constituem tecnologias de gênero ${ }^{31}$. Uma liturgia que se radicaliza na compulsão do exercício físico e nos transtornos alimentares marcadamente relevantes em segmentos mais jovens da população feminina ${ }^{32,33}$.

O corpo se realiza como espaço de significações em que o poder simbólico é disputado e exercido sob forma de uma hexis corporal legítima: a esbelteza, a altivez postural, o tônus muscular, o autocontrole alimentar, a disposição e a energia, enfim a realização da vida saudável. Os sistemas simbólicos enunciam relações de sentido para o mundo social, fato este que lhe confere força de sustentação ${ }^{29}$. O discurso produzido sobre o corpo inclui de modo disfarçado as taxionomias pertencentes à matriz de significações da cultura dominante, enquanto que o efeito da apropriação das formas de percepção do corpo consiste fundamentalmente na disseminação de sistemas de classificação comunicados pelo campo científico - higidez corporal, estilo de vida saudável, equilíbrio nutricional. A linguagem médica com seus signos é a própria linguagem do poder, aquela que comunica sobre um sistema de símbolos e objetos como discursos de verdade sobre a vida e de intervenção positiva na existência coletiva ${ }^{34}$.

O processo de simbolização protagonizado pelo corpo engendra significantes associados ao "belo", "feio", "desejável" ou "recusado", que enunciam juízos legítimos do sistema simbólico forjado no indivíduo. A subjetivação dos valores expressa e justifica de maneira eufemizada a unidade do sistema de poder. Um dos exemplos mais precisos desse processo pode ser extraído da geração de velhos, comumente designada de terceira idade. Incorporando valores da juventude - que agora para além da questão geracional sintetiza um "estado de espírito" - e assumindo novas possibilidades e formas de sociabilidades, a velhice passa a ser considerada como a "melhor idade". Utilidade, criatividade e dinamicidade passam a caracterizar o discurso corrente sobre os idosos; a autonomia e não mais a dependência é proclamada. Na lógica consumista, não só o bem-estar físico/biológico é importante, mas também a beleza "juvenil" - daí a tão explorada "indústria do rejuvenescimento" - mostrando a construída indissociabilidade entre saúde/estética. A responsabilidade individual, as escolhas realizadas ao longo da trajetória de vida e as novas classificações etárias são criadas como forma de culpabilizar e justificar quem não se enquadra nessa imagem idealizada da terceira idade. Inventa-se, conforme Britto da Motta ${ }^{35}$, "uma 'quarta idade', prenunciadora de uma quinta... E estas, quase ninguém quer estudar ou conhecer...”.

Por fim, novas construções imagéticas e reatualizações valorativas promoverão outras significações ao quadro das práticas corporais sem, contudo, alterar significativamente a essência dos reflexos.

\section{Breves considerações}

Em tempos modernos, a constituição e a afirmação do individualismo ocidental sobrepôs às dimensões dos valores comunitários do convívio a liberdade individual. Nossa sociedade "fez da crítica da realidade, da insatisfação com 'o que aí está' e da expressão dessa insatisfação uma parte inevitável e obrigatória dos afazeres da vida de cada um de seus membros"27.

A política-vida enquanto projeto emancipatório iluminista é a possibilidade da escolha dos estilos de vida e da mobilização reflexiva do eu e do corpo para atingir determinados "parâmetros existenciais". Esses processos de autorrealização de alguma maneira são possíveis porque há um enriquecimento da dimensão individual e politização da intimidade e dos estilos de vida.

O discurso da ciência sobre uma definição de estilo de vida saudável permite que a saúde deixe de ser uma condição natural e venha a tornar-se um dever eticamente fundamentado na condição humana da liberdade moderna. Esse direito às liberdades individuais apoia-se intensamente nos deveres ratificados pelos sistemas simbólicos, e posto está que a saúde e a beleza tornaram-se imperativos indissociáveis em nossa realidade. Assim, imagens contemporâneas da estética de superfície, da racionalização das técnicas corporais e da alimentação calculada, abastecem o acervo de símbolos necessários para a compreensão do movimento do pensamento que a sociedade moderna realiza acerca da condição humana. 


\section{Colaboradores}

RCF Giordani idealizou o texto, participou da pesquisa bibliográfica, redação e revisão final; e MTH Horochovski participou da redação e revisão final.

\section{Agradecimentos}

Este artigo é parte dos resultados da pesquisa "Sociabilidade e emoção na experiência alimentar", financiada pelo CNPQ. Além disso, as autoras gostariam de agradecer ao Centro de Assessoria de Publicação Acadêmica (CAPA - http:// www.capa.ufpr.br) da Universidade Federal do Paraná pela revisão e tradução do manuscrito deste artigo.

\section{Referências}

1. Tucherman I. Breve história do corpo e de seus monstros. Lisboa: Veja; 1999.

2. Baudrillard J. A sociedade de consumo. Lisboa: Edições 70; 1995.

3. Giddens A. Modernidade e Identidade. Rio de Janeiro: Zahar; 2002.

4. Mauss M. Ensaio sobre a dádiva. In: Maus M. Sociologia e antropologia. Rio de Janeiro: Cosac \& Naify; 2003. p. 183-314.

5. Ferreira J. O corpo sígnico. In: Alves PC, Minayo MC, organizadores. Saúde e doença: um olhar antropológico. Rio de Janeiro: Fiocruz; 2008. p. 101-112.

6. Bourdieu P. Sociologia. São Paulo: Ática; 1983.

7. Elias N. A sociedade de corte. Lisboa: Editorial Estampa; 1987.

8. Elias N. O processo civilizador - uma história dos costumes. Rio de Janeiro: Jorge Zahar Editor; 1994.

9. Ventura RCA estética da existência: Foucault e Psicanálise. Cogito 2008; 9:64-66.

10. Foucault M. Vigiar e punir: história da violência nas prisões. Petrópolis: Vozes; 1977.

11. Foucault M. Microfísica do poder. $12^{\mathrm{a}}$ ed. Rio de Janeiro: Graal; 1996.

12. Turner BS. El cuerpo y la sociedad, exploraciones en teoria social. México: Fondo de Cultura Económica; 1984.

13. Rodrigues JC. O corpo na história. Rio de Janeiro: Editora Fiocruz; 1999.

14. Weber M. A ética protestante e o espírito do capitalismo. Rio de Janeiro: Paz e Terra; 1989.

15. Breton D. Antropologia do corpo e modernidade. $3^{\mathrm{a}} \mathrm{ed}$. Petrópolis: Vozes; 2013.

16. Arnáiz MG. Comer bien, comer mal: la medicalización del comportamento alimentario. Salud Púb de México 2007; 49(3):236-242.

17. Sarti C. Corpo e doença no trânsito de saberes. Rev Bras Ci Soc 2010; 25(74):77-90.

18. Luz M. Natural, racional, social: razão médica e racionalidade científica moderna. Rio de Janeiro: Campus; 1988.

19. Canguilheim G. O normal e o patológico. $5^{\mathrm{a}} \mathrm{ed}$. Rio de Janeiro: Forense Universtária; 2000.

20. Heuer H. Corpo e vida: a crítica de Hannah Arendt à modernidade científica. Physis 2010; 20(02):533-549.

21. Dardot P, Laval C. A nova razão do mundo. São Paulo: Boitempo Editorial; 2017

22. Góes F, Villaça N. Em nome do corpo. Rio de Janeiro: Rocco; 1998.
23. Cerqueira MB. Digressões sobre saúde, envelhecimento e vida saudável na contemporaneidade. Mediações 2012; 17(2):26-40

24. Bagrichevsky M, Castiel LD, Vasconcellos-Silve PRV, Estevão A. Discursos sobre comportamento de risco à saúde e a moralização da vida cotidiana. Cien Saude Colet 2010; 15(Supl. 1):1699-1708.

25. Ferreira MS, Castiel LD, Cardoso MHC. A patologização do sedentarismo. Saúde Soc 2012; .21 (4):836-847.

26. Williams SJ, Martin P, GabeJ. The pharmaceuticalisation of society? A framework for analysis: The pharmaceuticalisation of society? Sociol Health Illn 2011; 33(5):710-725.

27. Bauman Z. Modernidade Líquida. Rio de Janeiro: Zahar; 2002.

28. Bourdieu P. O poder simbólico. Rio de Janeiro: Bertrand Brasil; 2000.

29. Bourdieu P. Meditações Pascalianas. Rio de Janeiro: Bertrand Brasil; 2001.

30. Gaudenzi P. Mutações biopolíticas e discursos sobre o normal: atualizações foucaultianas na era biotecnológica. Interface (Botucatu) 2017; 21(60):99-110.

31. Miskolsi R. Corpos elétricos: do assujeitamento à estética da existência. Estudos Feministas 2006; 14(3):681693.

32. Camarto TPP, Costa SPV, Uzunian LG, Viebig RF. Vigorexia: revisão dos aspectos atuais deste distúrbio de imagem corporal. Rev Bras Med Esporte 2008; 2(1):115.

33. Hay PJ. Epidemiologia dos transtornos alimentares: estado atual e desenvolvimentos futuros. Rev. Bras. Psiquiatr. 2002; 24(Supl. 3):13-17.

34. Rabinow P, Rose N. O conceito de biopoder hoje. Pol Trab Rev Cienc Soc 2006; 24:27-57.

35. Britto da Motta A. Envelhecimento e sentimento do corpo. In: Minayo MC, Coimbra CE, organizadores. Antropologia, saúde e envelhecimento. Rio de Janeiro: Fiocruz; 2002. p. 37-50.

Artigo apresentado em 27/08/2018

Aprovado em 08/04/2019

Versão final apresentada em 10/04/2019 